\title{
Blended Learning in a University EFL Writing Course: Description and Evaluation
}

\author{
Meihua Liu \\ Department of Foreign Languages and Literatures, Tsinghua University, Beijing, China
}

\begin{abstract}
Though blended learning had been continuously adopted in an Academic English Writing course (AEW) in a key university in Beijing, no attempts had been made to describe this new learning environment or investigate its effectiveness and impact. To fill in the gap, the present paper describes and evaluates blended learning in this AEW course in terms of course design, material development and presentation, assignment submission and grading, student involvement, teacher reflection, and student evaluation. Results showed that the students highly appreciated and benefited from the blended learning employed in the course in varying ways: it helped increase student-student and student-teacher interactions, reduce or even eliminate communication anxiety, motivate them to become (more) independent and autonomous learners, and enhance their academic English writing ability, and so on.
\end{abstract}

Index Terms —-blended learning, academic English writing, description, evaluation

\section{INTRODUCTION}

To optimize teaching and learning outcomes, computers have been increasingly applied in the teaching and learning of foreign languages in recent years (Beatty, 2003; Crook, 1994; Shang, 2007). Generally speaking, computer-assisted language teaching and learning (CALL) demonstrates a number of features in the enhancement of foreign/second language (FL/SL) learning, such as more language functions (Beatty, 2003; Chang, 2005; Crook, 1994), greater levels of participation (Gonza'lez-Bueno, 1998), reduced anxiety (Kessler, 2010; Ritter, 1993), and more motivation and interest and greater autonomy (Chang, 2005; Kessler \& Bikowski, 2010; Leakey \& Ranchoux, 2006; Vinther, 2011). "Multimedia-enhanced CALL is easily capable of creating learning situations of great fidelity or authenticity, both through the presentation of images of realia and through audio and video input that can present real world situations as realistically as television but with greater interaction" (Beatty, 2003, p. 22). Crook (1994) claimed that computer facilitated socially organized learning in the classroom rather than inhibited it. Chang's (2005) study revealed that students learning within a web-based environment with self-regulated learning strategies became more responsible for their own learning, more intrinsically orientated and more challengeable. Computers could also promote interaction through at least some of the four skills (listening, speaking, reading and writing) by providing a platform for collaboration and cooperation (Bahrani, 2011; Hwu, 1997).

When it comes to writing in a FL, FL learners usually face greater challenges, which can be attributed to a lack of language skills, culture-specific behaviors, and difficulty in interpreting hedged and indirect language (Baker \& Bricker, 2010; Bell \& Elledge, 2008; Jalilifar, 2010; Wold, 2011). Thus, both FL writing course instructors and learners often feel frustrated. Thus, as argued in Wold (2011), an effective instructional design model appropriate for online foreign language writing courses have not been found and designers of such a model should teach writing needs and should teach using a blended learning format (use of CALL and traditional classroom teaching and learning) instead of solely using an online learning format. It should be the same with traditional FL writing courses.

In a key university in Beijing, blended learning had been continuously employed in the Academic English Writing (AEW) course, yet not attempts had been made to describe this learning environment or investigate its effectiveness and impact, the same as what Beatty observed (2003). To fill in the gap, the present paper describes and evaluates blended learning in this AEW course in the University in terms of course design, material development and presentation, assignment submission and grading, student involvement, teacher reflection, and student evaluation.

\section{LITERATURE REVIEW}

Along with the introduction of computers into classrooms, CALL has been widely used in various fields to facilitate the teaching and learning of different aspects of foreign languages, among which the persuasive applications include word processing, games, corpus linguistics, computer-mediated communication, www resources, adapting other materials for CALL, and personal digital assistants (Bahrani, 2011; Chang, Chang, Chen \& Liou, 2008; Fidaoui, Bahous \& Bacha, 2010; Liou, Yang \& Chang, 2011; Romeo, 2008). These studies have predominantly revealed that CALL motivates learners and facilities learning. For example, Bush and Crotty (1991) compared videodisc instruction with traditional instruction and concluded that the use of videodisc exercises made practice inherently more meaningful than traditional text-based exercises. Montali and Lewandowski (1996) found that poor readers not only felt more 
successful with bimodal presentation, but were more successful in terms of comprehending content.

The use of technology has also long been introduced to complement traditional writing classes (Chang et al., 2008; Fidaoui et al., 2010; Goldberg, Russell, \& Cook, 2003; Liou et al., 2011; Shang, 2007). For example, Chang et al. (2008) developed an online collocation aid for EFL writers in Taiwan, aiming at detecting and correcting learners' miscollocations attributable to L1 interference. Relevant correct collocation as feedback messages was suggested according to the translation equivalents between learner's L1 and L2. The system utilized natural language processing (NLP) techniques to segment sentences in order to extract V-N collocations in given texts, and to derive a list of candidate English verbs that shared the same Chinese translations via consulting electronic bilingual dictionaries. After combining nouns with these derived candidate verbs as V-N pairs, the system made use of a reference corpus to exclude the inappropriate $\mathrm{V}-\mathrm{N}$ pairs and singled out the proper collocations. The results showed that the system could effectively pinpoint the miscollocations and provide the learner with adequate collocations that the learner intended to write but misused and that this online assistant facilitated EFL learner-writers' collocation use. Shang (2007) examined the overall effect of using email on the improvement of writing performance in aspects of syntactic complexity, grammatical accuracy and lexical density and investigated the relation between the number of email exchanges and writing performance. Data collected from 40 non-traditional EFL students enrolled in an intermediate reading class at a university in Taiwan showed that students made improvements on syntactic complexity and grammatical accuracy, that exchanging email messages with their peers at least four times might have a greater overall improvement on their writing performance, and that the email approach was a positive strategy that helped improve students' foreign language learning and attitudes towards English. Thus the researcher suggested designing an effective email task to enhance foreign language writing development and attitudes.

Even so, as argued in Wold (2011), an effective instructional design model appropriate for online foreign language writing courses have not been found and designers of such a model should teach writing needs and should teach using a blended learning format instead of solely using an online learning format. It should be the same with traditional foreign language writing courses, because blended learning have been found to offer a process-oriented environment for collaboration, communication, confidence building, and better attitudes about writing that does not exist when working exclusively online (Chih-Hua, 2008; Clark \& Olson, 2010; Colakoglu \& Akdemir, 2010).

Blended learning, as defined by Thorne (2003, p. 2), "blends online learning with more traditional methods of learning and development". Kupetz \& Ziegenmeyer (2005) referred to blended learning as "the purposeful arrangement of media, methods and ways of organizing learning situations through combining traditional media and methods with e-learning elements and possibilities" (pp. 179-180). As claimed by Neumeier (2005), blended learning consists of six parameters: (1) mode, (2) model of integration, (3) distribution of learning content and objectives, (4) language teaching methods, (5) involvement of learning subjects (students, tutors, and teachers), and (6) location. Among these six parameters, the two major modes are face-to-face and CALL. The mode which guides learners and where they often spend most of the time is called the lead mode; sequencing and negotiation of content is also done in the lead mode. The face-to-face phases are often obligatory while some online activities may not be (Neumeier, 2005). Giving learners this flexibility assumes that students are autonomous and will be responsible for their own learning (Grgurović, 2011).

Empirical studies on blended learning in language classes fall into comparison (Barr, Leakey, \& Ranchoux, 2005; Chenoweth \& Murday, 2003; Chenoweth, Green \& Youngs, 2001; Scida \& Saury, 2006) and noncomparison studies (Bañados, 2006; Grgurović, 2011; Stracke, 2007). The former examines the effectiveness of blended learning by comparing blended instruction (face-to-face together with CALL instruction) with traditional instruction (face-to-face without CALL instruction); and the latter investigates blended learning program design and implementation, and attitudes towards blended learning held by teachers and students. The blended learning classes in all the studies combined two modes: face-to-face in the classroom and CALL in the computer lab or student home via CALL programs, learning management systems (LMS), and the web, sometimes in conjunction with computer-mediated communication tools. Some studies made use of CALL technology features to set deadlines for exercises so students would complete them in a timely manner (Scida \& Saury, 2006). Some studies showed that the learners improved their proficiency in a language skill (usually speaking and reading) because they could practice it both in the CALL mode and face-to-face mode (Bañados, 2006; Barr et al., 2005). Some studies revealed that students needed more support from the instructor in addition to a more detailed schedule of assignments and deadlines (Chenoweth et al., 2006). In some studies, some students observed that lessons and exercises were not connected or that the distribution of learning content was not parallel and thus dropped out of the blended learning class (Adair-Hauck et al., 1999; Green \& Youngs, 2001; Stracke, 2007). Nineteen Asian students studying at an American university participated in Grgurović's (2011) study on the technology-enhanced blended-learning model in an ESL class in which the use of online CALL materials delivered through a commercially available LMS. The results indicated that the model successfully integrated modes and distributed learning content and that online speaking and pronunciation activities added value to instruction. The study also showed that the teacher's presence and assistance given to students during labs allowed for more individualized instruction than the teacher could provide in the classroom. In addition, the teacher participant believed that working on online materials in the lab helped less attentive students control their learning better than in the classroom.

Although blended learning has gained wide preference in recent years in recent years, it has not been well applied in writing courses or not much research has been done on blended learning in writing courses (Wold, 2011). The few 
research in this area has indicated that blended learning creates a supportive and motivating environment for learners and enhances their independent writing skills in terms of quality and quantity (Kupetz \& Ziegenmeyer, 2005; Thorne, 2003). Hence, more research is called for to better understand and use blended learning in FL/SL writing courses.

\section{FocUS OF THE PRESENT STUDY}

As an instructor of an Academic English Writing (AEW) course for five consecutive terms since the spring term in 2009 in the University in Beijing, I have been employing both traditional style of teaching and the use of CALL during the process of the teaching and learning of the course. I have noticed, as Montali and Lewandowski (1996) did, that poor writers not only felt more successful with bimodal presentation, but were more successful in terms of comprehending content in this environment. Though the University has long introduced the use of computer and Internet into the traditional classroom teaching and learning of various courses, few empirical studies have been done to examine its effectiveness and impact, as what Beatty observed (2003) almost a decade ago. Likewise, even though blended learning had been continuously adopted in the AEW course, no research had ever been attempted to investigate this blended learning environment. Hence, the present paper describes and evaluates blended learning in the AEW course. Nevertheless, since blended learning had been employed since the start of this AEW course which targeted advanced learners across disciplines of the University, including undergraduate English and non-English majors in all years of study, it was rather difficult to design a pre- and post-test investigation of the effectiveness of blended learning in this course. Consequently, the assessment of this blended learning was achieved in terms of course design, material development, assignment grading, student involvement, teacher reflection, and student evaluation in the present paper, as detailed in the following sections.

Blended learning in the present study, as Grgurović (2011, p. 100) defined, refers to "face-to-face teaching and learning supplemented by an online CALL component" delivered through an online classroom platform developed and maintained by the University. In this blend, the students met in the classroom once a week (90 minutes) with the instructor (traditional classroom teaching and learning) and spent at least one hour in the computer lab or in their dormitories working on CALL materials.

\section{Course description}

Course objective. This course aimed to train students to write academic English (e.g., extended essays, project reports and research articles) (more) competently, meanwhile training them how to conduct a basic research project (e.g., survey, interview, observation). More specifically, by the end of the course, the students should be able to: 1) understand what is required in academic assignments, 2) understand the process involved and the approach to study needed, 3) understand how to structure and format library-based academic assignment, 4) understand the conventions used for citations and create a list of references, 5) understand the conventions of presentation, 6) locate sources, demonstrate knowledge of topic and relevant literature, 7) read extensively, using a range of reading strategies, make notes, paraphrase and summarize, 8) incorporate information from sources into writing and avoid plagiarism, 9) understand the need for a critical approach to academic reading and writing, 10) understand the need to develop own coherent argument, 11) know a range of grammatical structures and lexis appropriate to academic writing and use them properly, and 12) write competently, using a range of cohesive devices.

Course design. Some studies attribute poor instructional outcomes in FL writing to the instructional design of the courses, such as not integrating components to stimulate motivation in a topic that can often seem challenging for students (Colakoglu \& Akdemir, 2010; Coryell \& Chlup, 2007). To stimulate students' motivation and interest in academic English writing, the AEW course in the present study adopted blended learning, namely integrating technology into traditional classroom teaching and learning, in that it clearly has many advantages over using online or traditional formats (Bahrani, 2011; Wold, 2011).

The 16-week long AEW course in the present study generally divided teaching and learning into odd and even weeks: even weeks for lecturing and odd weeks for review (teacher review, peer review and group review) and discussion. Lecturing consisted of eight topics: introduction to academic English writing, introduction (with emphasis on the research problem and research statement) and conclusion, variables and sampling, literature review, primary data-collection methods, research design, results and discussion, and the writing up of the whole paper. During the term, the students had to complete five written tasks: a summary of an academic paper, an introduction and conclusion of a given paper, literature review report, research design, and a complete research paper. Towards the end of the course, each student was required to give an oral presentation of his/her research to the class. All the assignments, as reflected later by the course teacher and the students, required much reading and writing and were appropriately challenging, with each assignment gradually more competing than the preceding one. The teacher and the students met face-to-face once a week, each meeting lasting 90 minutes. For other times, they met online for individual and/or group discussion via a platform called Online Classroom (OC), a subplatform of a larger one created and supported by the University which offered information and links about almost every aspect of campus life such as course information and personal research projects to each teacher and student. Closely related to the present study was the OC platform, which provided a fairly convenient channel for interactions between the course teacher and the students and among the students, as presented below (see Diagram 1). Via this platform, the course teacher could make announcements, upload course materials, create new learning content, assign homework, check assignments, organize discussions, answer questions, 
and view student profiles; and the students could download course materials, upload assignments or other files, ask questions, and initiate or participate in discussions. Though the course teacher could create new learning content and upload it to this platform, s/he could not make any learning content out of it. Nevertheless, the larger platform provided links to various available resources for both teachers and students to help create new learning content. Because of the platform and the easy access to Internet on campus, various computer or internet related ways (e.g., google, email, and online dictionaries) were encouraged/used to foster the learning of academic English writing as well as the language, such as searching for related works, writing up a review of related works, designing a research study, analyzing data, and writing up the paper, as suggested by Loucky (2005) and Sha (2010) and happened in Grgurović's (2011) course. And the course teacher and the students could communicate anytime and anywhere.

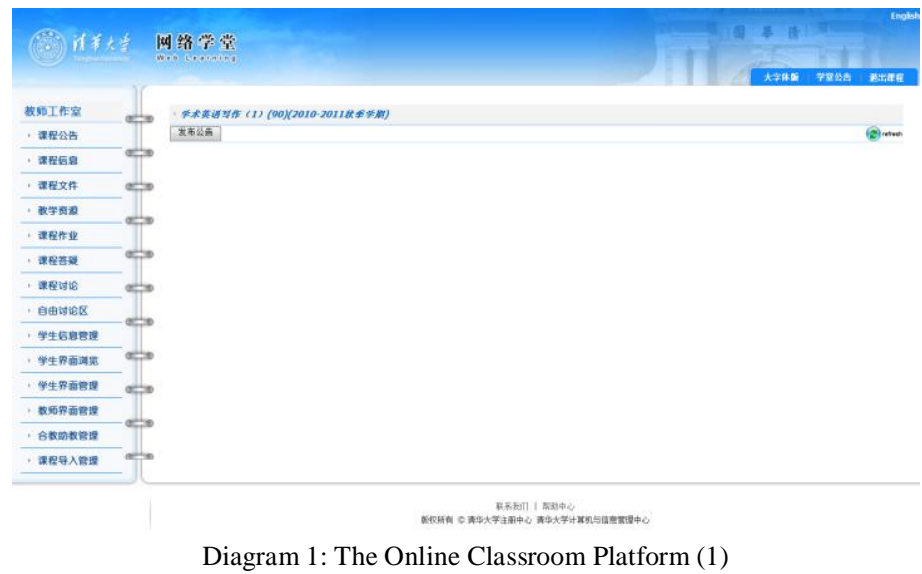

\section{Material development and presentation}

The development of course materials abided by the following widely acknowledged rules: need, authenticity, text difficulty, range and style (Allwright, 1981; Benson \& Voller 1997; Nunan 1989; Richards, 2001). To meet the specific needs of this AEW class, material development evolved around the aim of developing the ability to write academic English competently. For this purpose, all materials were taken from worldwide used academic writing textbooks (e.g., those compiled by McCormack and Slaght (2006) and Wyrick (2008)) and academic journals in various disciplines, with difficulty and topic scaffolded to tailor the students' academic knowledge and English proficiency. Likewise, the students were instructed explicitly different parts of an academic paper and were then trained to write different parts accordingly before they could finally produce a full research essay.

Meanwhile, as Krashen (1984) argued that it was reading that gave the writer the 'feel' for the look and texture and maintained that writing competence could be best derived from large amounts of reading of the target language, which was supported by many other researchers (Machin \& Ward, 2007; Shanahan \& Lomax, 1986), lots of articles from academic journals on diverse subjects were selected for the students to read and model on during the process of the AEW course.

As Beatty (2003, p. 142) said, "In a CALL program, it is important to have information structured on a series of levels encouraging readers operating at various levels, at any point, to delve deeper into explanations of the content", the course lectures and materials were developed and presented according to the level of difficulty and the progress of academic English writing during the term, as shown in Diagram 2.

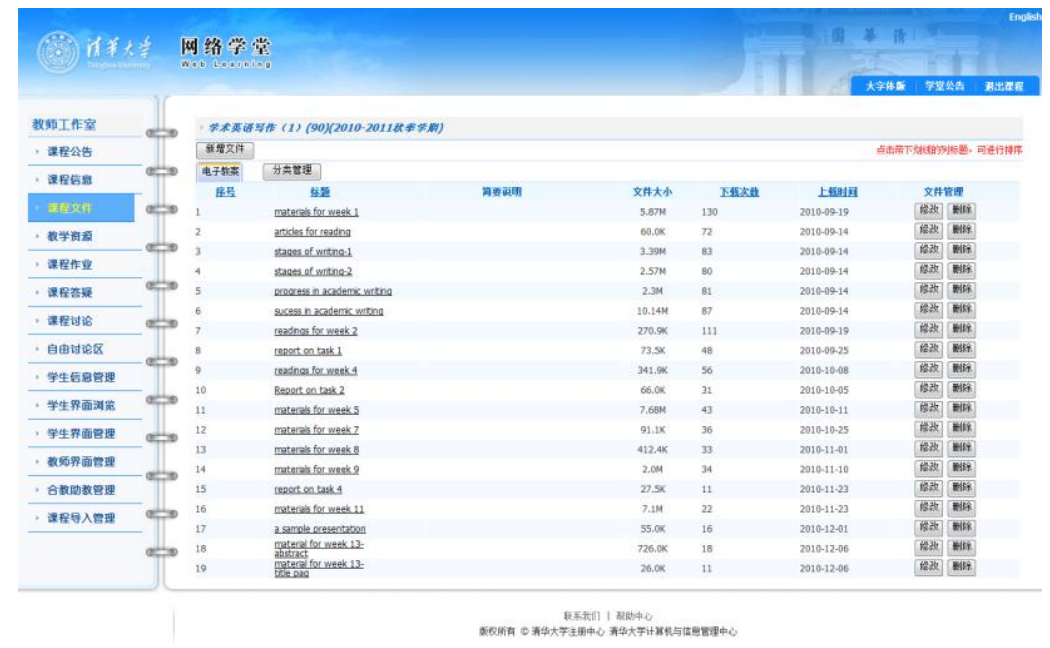

Diagram 2: The Online Classroom Platform (2) 


\section{Assignment submission and grading}

The students' written work was submitted via the OC platform. Since the course emphasized process-oriented and project-based writing and enormously encouraged revision and rewriting, the students might submit several drafts of the same writing task. Thanks to the platform, it was extremely easy for both the teacher and students to check and track the submission of assignments, as illustrated in Diagram 3.

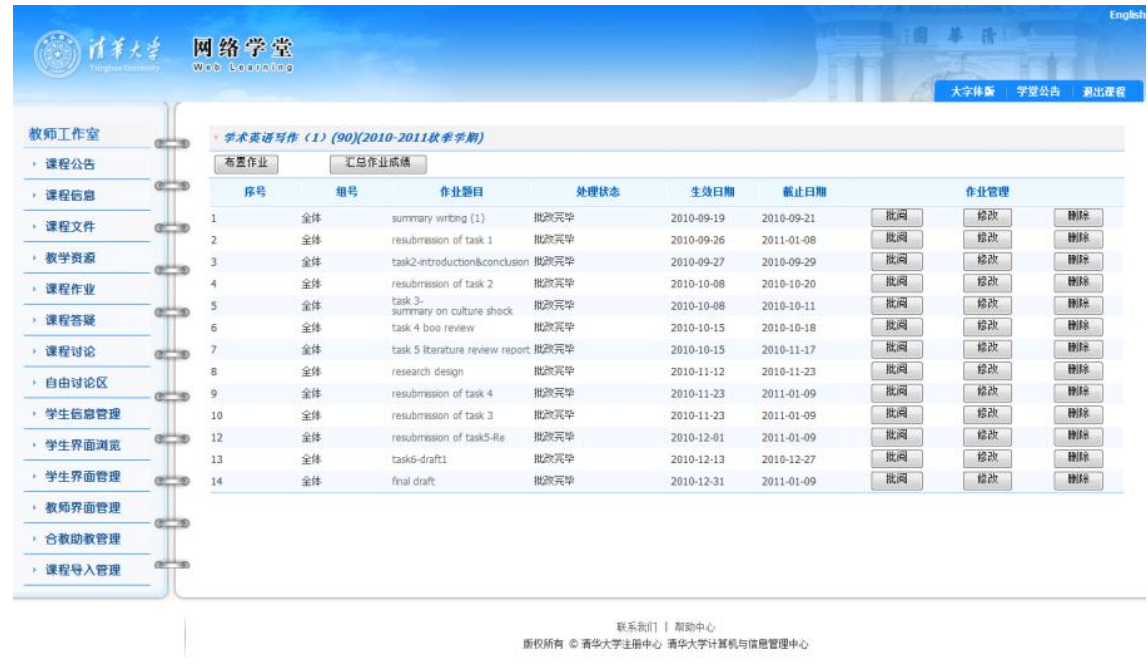

Diagram 3: The Online Classroom Platform (3)

All the submitted assignments were read and commented with a tracking system from three levels: sentence level, paragraph level, and discourse level, as suggested and practiced by Yang (2004). Sentence level grading focused on word choice and collocation, as well as grammatical and spelling mistakes, which were often highlighted for self-correction; paragraph-level grading was mainly concerned with paragraph structure, paragraph development and coherence, and discourse-level grading involved discourse structure, thesis development, and global coherence and cohesion, as illustrated by the following example.

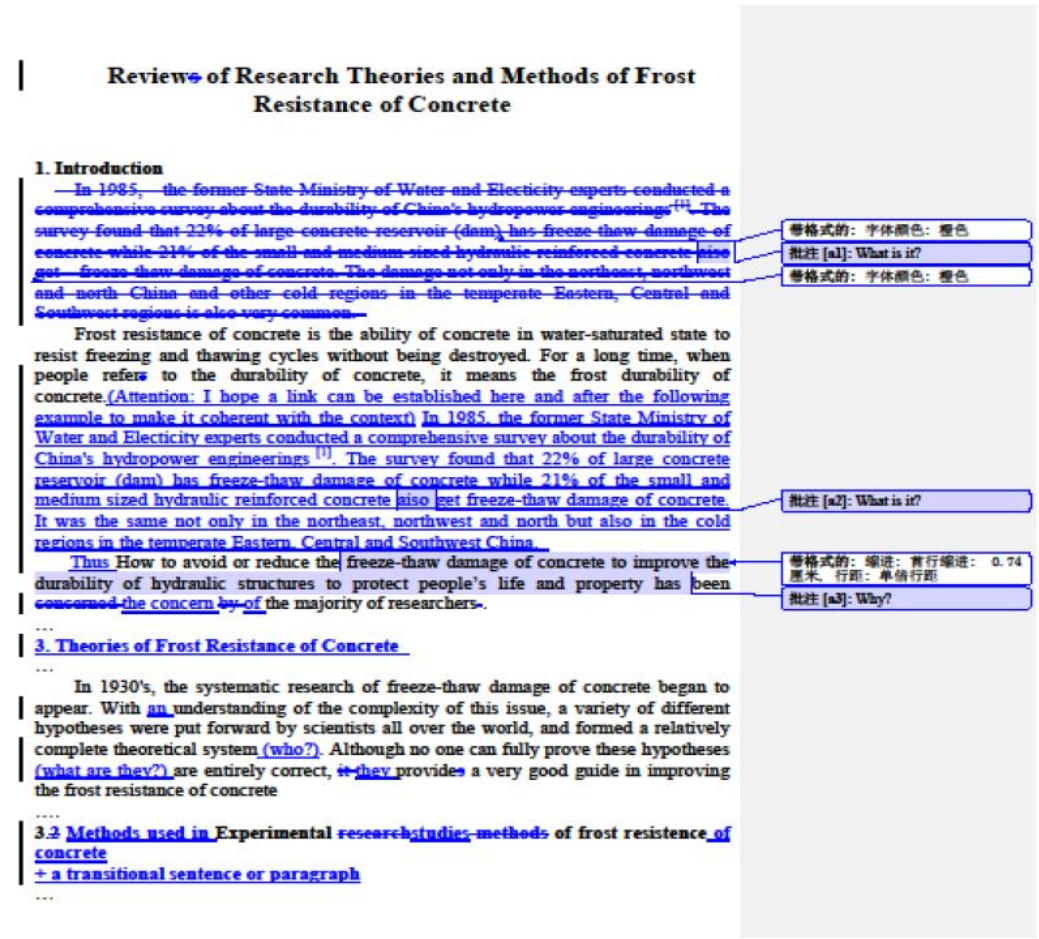

Thus, it was easy for the students to notice the mistakes they had made, the changes, revisions and suggestions given by the course teacher at different levels. With everything electronic, it was also easy for them to compare and contrast different drafts of the same writing task and read each other's writing. Meanwhile, since all the assignments were submitted and graded via the same platform, the students were able to obtain immediate feedback on progress.

Student involvement 
During the term, the students were required to be highly involved in every stage of the process of developing the ability to write academic English competently. To access the learning content and complete their assignments, they ought to check the OL platform frequently to download and upload files of various kinds; they had to use various means to search for related articles and books in their own respective fields for different purposes; they were required to critically read the articles and books they had found, model on them, and cite appropriately in their own writing; they were encouraged to peer review each other's writing and report their research to the class for public discussion; and they were strongly advised to reflect on their own writing at certain intervals, post their questions and comments on the OC platform, and participate in various discussions initiated at the platform. More importantly, they were repeatedly encouraged and motivated to update their literature review, reflect on their thinking and writing, and revise their writing on the same topic until they felt satisfied, as Turuk (2008) noticed that students learned (more) effectively when reflecting on their new surroundings and changing their beliefs based on these reflections. Consequently, the locus of control varied from task to task and from person to person, as happened in Grgurović's (2011) study.

\section{Teacher reflection}

The course teacher, a Ph.D in applied linguistics, was in her late thirties and experienced in teaching English writing for general and academic purposes. When the present study was conducted, she was asked to comment on the blended learning environment in her AEW course and its impact on the students and their learning of academic English writing. When looking back, the course teacher believed that the OC platform was extremely useful, in that it helped reduce the students' anxiety and increase interactions between the teacher and the students and among the students, which ultimately facilitated both the teaching and learning of academic English writing. This is best illustrated by her comments,

because of the platform, we can send messages, download and/or upload materials any time. Because it is online, the students feel more comfortable and less anxious to ask questions and discuss among themselves and with me. Given the fact that both the students and I can obtain immediate feedback from each other, it's more helpful for us to adjust our teaching and learning in time.

As reported in Ritter's (1993) study, the students' anxiety levels were lowered when they used the technology and they thus became more active participants in the learning process. Liu, Moore, Graham and Lee (2003) also commented that " positive affective states (i.e., enjoyment, anxiety) can provide additional incentive for students to learn. A positive emotional state could help increase student enthusiasm for a subject matter' (p. 263). Likewise, the students' anxiety levels were (greatly) reduced in the present study so that they became more confident and willing to interact with their peers and the course teacher.

Feedback is essential in any teaching and learning setting (Wold, 2011), which pushes both teaching and learning on the right track. As found in Liou et al. (2011), the OC platform in the present study enabled the possibility of immediate feedback, which not only facilitated both teaching and learning but motivated the students to work harder.

Meanwhile, the course teacher commented that because the students were highly involved in every stage of the process of learning academic English writing, as evidenced in their behavior in class and submitted assignments, they were fairly motivated and did unexpectedly well in academic English writing. Learners' motivation has been found to be improved in a computer-assisted learning environment in a number of studies (Chang, 2005; Fidaoui et al., 2010; Guthrie \& Richardson, 1995). As Chang (2005) commented, web-based learning often places a variety of demands on learners that exceed those typically experienced in traditional teacher-centered classrooms. Learners in this environment are encouraged to construct knowledge for themselves and to have the control of their own learning. Consequently, they are more motivated because it provides them an environment to take charge of their own learning and control their own learning process.

\section{Student evaluation}

As required by the University, each student enrolled in a course must fill in a questionnaire to evaluate the course toward the end of the term so that s/he could register courses for the coming term. This evaluation questionnaire consisted of 11 items and an open-ended question. These 11 items, all on a scale of 1-100, measured the following dimensions: teacher's attitude (item 1), teaching (items 2-3), the teacher (items 4 \& 8-9), teaching materials (item 5), assignment (item 6), assessment (item 7), benefit from the course (item 10), and an overall evaluation of the course (item 11). The open-ended question aimed to collect students' comments on any aspect of the course. Though its validity and reliability had been repeatedly challenged by researchers and professors across disciplines over the years of the University, this questionnaire had been continuously employed in the University as a principal approach to evaluate teachers' teaching of various courses in different areas targeting at diverse student populations. True be the challenges, this questionnaire might not objectively evaluate a course. Nevertheless, since it had been consistently administered across terms, meaning varying groups of students used the same questionnaire to evaluate the same course or even the same course teacher, this type of data collected across terms might to a large extent objectively reflect how the course was taught and how effective it was.

The students of this Academic English Writing (AEW) course were generally advanced undergraduate learners of English from various disciplines and years of study, including English majors, of the University. Each term, around 10-20 of them, with an age range of 17-22, registered for and stayed in the course till the end.

Because of some reasons, this AEW course in the present study was exempt from student evaluation in some terms. 
Hence, the results of student evaluation of only three terms were available, as summarized in Table 1.

TABLE 1:

STUDENT EVALUATION OF THE AEW COURSE ACROSS TERMS

\begin{tabular}{|c|c|c|c|}
\hline- & $\begin{array}{l}2009 \text { spring } \\
(\mathrm{N}=17)\end{array}$ & $\begin{array}{l}2010 \text { spring } \\
(\mathrm{N}=13)\end{array}$ & $\begin{array}{l}2011 \text { Autumn } \\
(\mathrm{N}=11)\end{array}$ \\
\hline $\begin{array}{l}\text { (1) The teacher is enthusiastic, serious, dedicated, and } \\
\text { educational. }\end{array}$ & 96.98 & 100 & 100 \\
\hline $\begin{array}{l}\text { (2) The teaching is clear, with a focus on the important and } \\
\text { difficult points. }\end{array}$ & 90.13 & 100 & 100 \\
\hline $\begin{array}{l}\text { (3) The teaching is vivid, attractive and } \\
\text { inspiring. }\end{array}$ & 92.43 & 92.56 & 97.82 \\
\hline $\begin{array}{l}\text { (4) The teacher interacts with the students, encourages them to } \\
\text { ask questions, and guide them on the right track. }\end{array}$ & 94.87 & 100 & 100 \\
\hline (5) Course materials are helpful. & 92.43 & 98.34 & 97.78 \\
\hline $\begin{array}{l}\text { (6) Assignments and other types of training facilitate the } \\
\text { learning of the course. }\end{array}$ & 96.98 & 100 & 100 \\
\hline (7) Assessment and tests motivate the students to learn more. & 92.43 & 98.34 & 95.56 \\
\hline $\begin{array}{l}\text { (8) The teacher encourages originality and independent } \\
\text { thinking. }\end{array}$ & 88.92 & 98.34 & 97.82 \\
\hline (9) The teacher gives advice on after-class learning. & 100 & 100 & 100 \\
\hline (10) I benefit from this course. & 96.98 & 98.34 & 97.82 \\
\hline (11) Overall evaluation of the course. & 96 & 100 & 95 \\
\hline
\end{tabular}

Note: $\mathrm{N}=$ number of students

As noted from Table 1, the students of each term highly evaluated the course, with a score range of 95 to 100 (item 11). The mean score of each item across terms was also high, ranging from 88.92 to 100 . Alternatively, the students of the three terms all believed that the teacher was enthusiastic, dedicated, inspiring, encouraging, and helpful, that the teacher interacted with them well, and that they enormously benefited from the course.

Consistent with the survey results, the students' responses to the open-ended question revealed that they highly evaluated the teacher and the course. Among the 20 students of the three terms who answered the open-ended question, $20(100 \%)$ commented that they were deeply impressed and motivated by the teacher's responsibility and that they gained a lot from the course. $17(85 \%)$ reflected that the OC platform provided for them a convenient channel for greater communication with the others, as reported in many other studies (Gonza'lez-Bueno, 1998; Liu et al., 2003; Ritter, 1993). 16 (80\%) believed that they became more confident users of various computer and Internet-related approaches to help them through different stages of academic English writing, as found in Kessler (2010). 11 (55\%) claimed that the OC platform motivated them to become more independent and autonomous learners, as found in Fidaoui et al. (2010), Bahrani (2011) and Leakey and Ranchoux (2006) who discovered that blended learning enhanced student motivation and promoted their autonomy in the use of the multimedia environment.

$10(50 \%)$ of the respondents wrote that their English was also greatly improved by learning how to write academic English (more) competently. $6(30 \%)$ maintained that the OC platform enabled them to maximize their interaction and gain from each other and the teacher, as reported by their counterparts in Roed (2003) and Ritter (1993).

$4(20 \%)$ of the 20 respondents were so happy that they successfully survived the course though it was tough and challenging.

As such, as happened in Wiebe and Kabata's (2010) and Mathews-Aydinli and Elaziz's (2010) studies, both the course teacher and the students held fairly positive attitudes towards the use of blended learning in the Academic English Writing course and appreciated highly the approach.

\section{CONCLUSIONS AND IMPLICATIONS}

The present paper describes and evaluates the blended learning in an Academic English Writing course in a key university in Beijing in terms of course design, material development and presentation, assignment submission and grading, student involvement, teacher reflection, and student evaluation.

Aiming to train students to write academic English (more) competently and largely depending on the online classroom platform, this Academic English Writing course had employed various computer and Internet-related approaches to involve, motivate and inspire the students to be actively engaged in various stages of academic English writing. Both the course teacher's reflections and student evaluation across terms revealed that the students highly appreciated and benefited from this blended learning in varying ways: it helped increase student-student and student-teacher interactions, reduce or even eliminate communication anxiety, motivate the students to become (more) independent and autonomous learners, and enhance their academic English writing ability, and so on, as found in numerous existing studies (Kessler \& Bikowski, 2010; Kupetz \& Ziegenmeyer, 2005; Roed, 2003; Vinther, 2011; Wiebe \& Kabata, 2010).

As revealed in the present study as well as other studies (Bahrani, 2011; Beatty, 2003; Roed, 2003; Vinther, 2011; Wiebe \& Kabata, 2010), CALL has many advantages over traditional classroom teaching and learning such as providing motivation and autonomy for learners, flexible learning, immediate and detailed feedback, reducing anxiety, 
and enhancing student involvement and participation. The use of hypertext, hypermedia, and multimedia enables teaching and learning different from the traditional way, which often seems to be more motivating and inspiring. Nevertheless, in spite of the positive feedback from the students in successive years in the present study, it should be noted that computer can never replace teachers, who should be responsible for developing appropriate CALL programs and caring about students' progresses, as suggested in Nunan (1987) and Williams (1998). Teachers, as suggested by Richard (1997), need to select learning activities, prepare students for new learning, present learning activities, ask questions, conduct drills, check students' understanding, provide opportunities for practice of new items, monitor students' learning, give feedback on student learning and review and re-teach when necessary.

Finally, due to various constraints, several limitations exist in the present study, the most striking of which is that the subject matter emerged from the data but was not the initial focus of investigation. The questionnaire, in particular, was not designed to assess the effectiveness of the blended learning adopted in the Academic English Writing course, but for a more general purpose. Hence, to better examine the impact of blended learning in writing courses in Chinese EFL contexts, more systematic investigations are required. In particular, a pre- and post-test design is called for to assess the effectiveness and impact of this blended mode of learning academic writing English.

\section{ACKNOWLEDGEMENT}

The present study was sponsored by the Humanities and Social Science Revitalization Fund Research, Tsinghua University (No.: 2010WKYB019).

\section{REFERENCES}

[1] Adair-Hauck, B., Willingham-McLain, L., \& Youngs, B. E. (1999). Evaluating the integration of technology and second language learning. CALICO Journal, 17, 296-306.

[2] Bahrani, T. (2011). Computer assisted language learning—some aspects. Language in India, 11(9), 271-278.

[3] Baker, W., \& Bricker, R.H. (2010). The effects of direct and indirect speech acts on native English and ESL speakers' perception of teacher written feedback. System, 38, 75-84.

[4] Bañados, E. (2006). A blended-learning pedagogical model for teaching and learning EFL successfully through an online interactive multimedia environment. CALICO Journal, 23, 533-550.

[5] Barr, D., Leakey, J., \& Ranchoux, A. (2005). Told like it is! An evaluation of an integrated oral development project. Language Learning \& Technology, 9(3), 55-78.

[6] Beatty, K. (2003). Teaching and researching computer-assisted language learning. London/New York: Pearson education Limited.

[7] Bell, D. C., \& Elledge, S.R. (2008). Dominance and peer tutoring sessions with English language learners. The Learning Assistance Review, 13, 17-30.

[8] Bush, M. D., \& Crotty, J. (1991). Interactive videodisc in language teaching. In W. F. Smith (ed.), Modern technology in foreign language education: applications and projects (pp. 75-96). Lincolnwood, IL: National Textbook Co.

[9] Chang, M-M. (2005). Applying self-regulated learning strategies in a web-based instruction —an investigation of motivation perception. Computer Assisted Language Learning, 18(3), 217-230.

[10] Chang, Y-C., Chang, J. S., Chen, H-J., \& Liou, H-C. (2008). An automatic collocation writing assistant for Taiwanese EFL learners: A case of corpus-based NLP technology. Computer Assisted Language Learning, 21(3), 283-299.

[11] Chenoweth, N. A., \& Murday, K. (2003). Measuring student learning in an online French course. CALICO Journal, 20, 285-314.

[12] Chenoweth, N. A., Ushida, E., \& Murday, K. (2006). Student learning in hybrid French and Spanish courses: An overview of language online. CALICO Journal, 24, 115-145.

[13] Chih-Hua, K. (2008). Designing an online writing system: Learning with support. RELC Journal, 39, $285-299$.

[14] Clark, M., \& Olson, V. (2010). Scientific method: A blended instructional model. Journal of College Teaching and Learning, 7 , 35-38.

[15] Colakoglu, O., \& Akdemir, O. (2010). Motivational measure of the instruction compared: Instruction based on the ARCS motivation theory vs traditional instruction in blended courses. Turkish Online Journal of Distance Education, 11, 73-89.

[16] Coryell, J.E., \& Chlup, D.T. (2007). Implementing e-learning components with adult English language learners: Vital factors and lessons learned. Computer Assisted Language Learning, 20, 263-278.

[17] Crook, C (1994). Computers and the collaborative experience of learning. London: Routledge.

[18] Fidaoui, D., Bahous, R., \& Bacha, N. N. (2010). CALL in Lebanese elementary ESL writing classrooms. Computer Assisted Language Learning, 23(2), 151-168.

[19] Goldberg, A., Russell, M., \& Cook, A. (2003). The effect of computers on student writing: A meta-analysis of studies from 1992 to 2002. The Journal of Technology, Learning, and Assessment, 2(1), 1-52.

[20] Gonza 'ez-Bueno, M. (1998). The effect of electronic mail on Spanish L2 discourse. Language Learning and Technology, 1(2), $55-70$.

[21] Green, A., \& Youngs, B. E. (2001). Using the web in elementary French and German courses: Quantitative and qualitative study results. CALICO Journal, 19, 89-123.

[22] Grgurović, M. (2011). Blended learning in an ESL class: a case study. CALICO Journal, 29(1), 100-117.

[23] Guthrie L. F., \& Richardson, S. (1995). Turned on to language arts: Computer literacy in primary grades. Educational Leadership, 53(2), $14-17$.

[24] Hwu, F. (1997). Providing an effective and affective learning environment for Spanish phonetics with a hypermedia application. CALICO Journal, 14(2-4), 115-134. 
[25] Jalilifar, A. (2010). Thematization in EFL students' composition writing and its relation to academic experience. RELC Journal, $41,31-45$

[26] Kessler, G. (2010). Fluency and anxiety in self-access speaking tasks: the influence of environment. Computer Assisted Language Learning, 23(4), 361-375.

[27] Kessler, G., \& Bikowski, D. (2010). Developing collaborative autonomous learning abilities in computer mediated language learning: attention to meaning among students in wiki space. Computer Assisted Language Learning, 23(1), 41-58.

[28] Kupetz, R., \& Ziegenmeyer, B. (2005). Blended learning in a teacher training course: integrated interactive e-learning and contact learning. ReCALL, 17(2), 179-196.

[29] Leakey, J., \& Ranchoux, A. (2006). BLINGUA. A blended language learning approach for CALL. Computer Assisted Language Learning, 19(4-5), 357-372.

[30] Liou, H.-C., Yang, P.-C., \& Chang, J. S. (2012). Language supports for journal abstract writing across disciplines. Journal of Computer-assisted Learning, 28(4), 322-335.

[31] Liu, M., Moore, Z., Graham, L., \& Lee, S. (2003). A look at the research on computer-based technology use in second language learning: A review of the literature from 1990 -2000. Journal of Research on Technology in Education, 34(3), 250 $-273$.

[32] Loucky, J. P. (2005). Combining the benefits of electronic and online dictionaries with CALL web sites to produce effective and enjoyable vocabulary and language learning lessons. Computer Assisted Language Learning, 18(5), 389-416.

[33] Mathews-Aydinli, J., \& Elaziz, F. (2010). Turkish students' and teachers' attitudes toward the use of interactive whiteboards in EFL classrooms. Computer Assisted Language Learning, 23(3), 235-252.

[34] McCormack, J., and Slaght, J. (2006). English for academic study: extended writing and research skills. Beijing: Higher Education Press.

[35] Montali, J., \& Lewandowski, L. (1996). Bimodal reading: benefits of a talking computer for average and less skilled readers. Journal of Learning Disabilities, 29(3), 271-279.

[36] Neumeier, P. (2005). A closer look at blended learning: Parameters for designing a blended learning environment for language teaching and learning. ReCALL, 17, 163-178.

[37] Nunan, D. (1987). Methodological issues in research. Adelaide: National Curriculum, Resource Center.

[38] Richard, J. C. (1997). Preparing language teachers for tomorrow's language classrooms. In G. M. Jacobs (ed.), Language classrooms of tomorrow: issues and responses (pp. 195-208). Singapore: SEAMEO Regional Language Center.

[39] Ritter, M. (1993). That's us! A book about ourselves: an EFL project with intermediate learners, incorporating the computer as a tool. CALICO Journal, 10(4), 57- 69.

[40] Roed, J. (2003). Language learner behavior in a virtual environment. Computer Assisted Language Learning, 16(2-3), 155-172.

[41] Romeo, K. (2008). A web-based listening methodology for studying relative clause acquisition. Computer Assisted Language Learning, 21(1), 51-66.

[42] Scida, E. E., \& Saury, E. R. (2006). Hybrid courses and their impact on student and classroom performance: A case study at the University of Virginia. CALICO Journal, 23, 517-531.

[43] Sha, G. (2010). Using Google as a super corpus to drive written language learning: a comparison with the British National Corpus. Computer Assisted Language Learning, 23(5), 377-393.

[44] Shang, H-F. (2007). An exploratory study of e-mail application on FL writing performance. Computer Assisted Language Learning, 20(1), 79-96.

[45] Stracke, E. (2007). A road to understanding: A qualitative study into why learners drop out of a blended language learning (BLL) environment. ReCALL, 19, 57-78.

[46] Thorne, K. (2003). Blended learning: How to integrate online and traditional learning. London: Kogan Page.

[47] Turuk, M. (2008). The relevance and implications of Vygotsky's sociocultural theory in the second language classroom. Annual Review of Education, Communication \& Language Sciences, 5, 244-262.

[48] Vinther, J. (2011). Enhancing motivation with cultural narratives in computer-mediated communication. Computer Assisted Language Learning, 24(4), 337-352.

[49] Wiebe, G., \& Kabata, K. (2010). Students' and instructors' attitudes toward the use of CALL in foreign language teaching and learning. Computer Assisted Language Learning, 23(3), 221-234.

[50] Williams, N. (1998). Educational multimedia: where's the interaction. In M. Montreith (ed.), IT for learning enhancement (pp. 153-170). Heereweg, Netherlands: Swets \& Zeitlinger.

[51] Wold, K. A. (2011). Blending theories for instructional design: creating and implementing the structure, environment, experience, and people (SEEP) model. Computer Assisted Language Learning, 24(4), 371-382.

[52] Wyrick, J. (2008). Steps to writing well. Beijing: Peking University Press.

[53] Yang, Y. (2004). Experience English writing. Beijing: Higher Education Press.

Meihua Liu, Ph.D, is associate professor at the Department of Foreign Languages and Literatures, Tsinghua University. Her research interests mainly include teaching and learning of English in Chinese EFL contexts, reticence and anxiety, second/foreign language writing, and study abroad. 